\title{
О ТЕРМОСТОЙКОСТИ И ГОРЮЧЕСТИ ПОЛИМЕРНЫХ КОМПОЗИЦИОННЫХ МАТЕРИАЛОВ, АРМИРОВАННЫХ ХИМИЧЕСКИМИ ВОЛОКНАМИ
}

Перспективность применения химических волокон в качестве армирующих систем при создании полимерных композиционных материалов (ПКМ) конструкционного и строительного назначения не вызывает сомнений $[1,2]$. Расширить области применения таких ПКМ возможно приданием им пониженной горючести, меньшей токсичности продуктов разложения, повышенной термостойкости, жесткости, прочности при растяжении и сжатии. Этот комплекс ценных специфических свойств может быть достигнут путем применения модифицированных волокон.

Данная статья и посвящена решению этих вопросов. В целях снижения горючести ПКМ использовались армирующие волокна, модификация которых проводилась различными P, N, Cl-содержащими соединениями - антипиренами. Для улучшения физико-механических свойств ПКМ модификацию капрона осуществляли новолаком на стадии синтеза поликапроамида.

При исследовании горения полимеров особенно важно всестороннее изучение стадий процесса, в которых происходят фазовые и химические превращения веществ. Общая картина процесса горения может быть составлена на основе изучения массовых скоростей пиролиза и горения, выхода карбонизированного остатка, состава газов пиролиза и др. При определении рациональных областей применения эпоксидных ПКМ, армированных капроном, модифицированным новолаком, необходимо знать их устойчивость к действию температур широкого диапазона и токсичность продуктов деструкции.

Изучение пиролиза проводили методом термогравиметрического анализа (ТГА) на дериватографе системы «Paulik-Paulik-Erdei» в среде воздуха при скорости нагрева $10 \%$ мин.

Состав газов пиролиза изучали методом ступенчатой пиролизной газовой хроматографии (СПГХ) в среде гелия в интервале температур 373-873 К. Показатели горючести оценивали по ГОСТу 12.1.044-84. Поверхностную структуру кокса изучали на растровом электронном микроскопе РЭМ-200.

Исследованные образцы ПКМ получены методом компрессионного прессования при температуре $365 \pm 5 \mathrm{~K}$ для эпоксидных и при $423 \pm 5 \mathrm{~K}$ для фенольных материалов, при давлении $8 \mathrm{MПа} \mathrm{и} \mathrm{продолжительности}$ прессования 3 мин/мм толщины образца.

Для модификации вискозных волокон (ВВ) в целях снижения горючести использовали:

- полифосфат аммония (ОЗВ-1);

- фосфорнокислую соль полиэтиленполиамина, количество антипирена на волокне составляло $25,3 \%$ мас. (О3В-2) и $30,5 \%$ мас. (О3В-3);

- диамидометилфосфонат (ОЗВ-4);

- триоксиметилфосфин (ОЗВ-5);

- фослон А (ОЗВ-6);

- фосфолан (ОЗВ-7), 
Данные термогравиметрического анализа волокон и полимерных композиционных материалов на их основе

\begin{tabular}{|c|c|c|c|c|c|c|}
\hline \multirow[b]{2}{*}{ Материал } & \multicolumn{6}{|c|}{ Коксовый остаток, \% } \\
\hline & $373 \mathrm{~K}$ & $473 \mathrm{~K}$ & $573 \mathrm{~K}$ & $673 \mathrm{~K}$ & $773 \mathrm{~K}$ & $873 \mathrm{~K}$ \\
\hline
\end{tabular}

Волокна

$\begin{array}{lcccccr}\text { ВВ исходное } & 94,5 & 91,2 & 47,1 & 24,5 & 13,6 & 5,0 \\ \text { O3В-4 } & 100 & 89,0 & 46,0 & 39,0 & 31,0 & 26,0 \\ \text { O3В-5 } & 98,6 & 98,0 & 53,5 & 46,8 & 43,0 & 36,4 \\ \text { O3В-6 } & 92,3 & 90,5 & 52,5 & 33,0 & 28,0 & 20,5\end{array}$

Композиционные материалы

$\begin{array}{lllllll}\text { ВВ исходное +ЭД-20 } & 97,5 & 95,9 & 71,2 & 41,3 & 35,5 & 23,5 \\ \text { ОЗВ-4+ЭД-20 } & 97,5 & 94,0 & 63,0 & 55,3 & 42,7 & 28,5 \\ \text { ОЗВ-5+ЭД-20 } & 98,5 & 95,0 & 70,5 & 50,0 & 41,0 & 29,5 \\ \text { ОЗВ-6+ЭД-20 } & 99,0 & 95,4 & 62,0 & 49,0 & 39,0 & 28,5\end{array}$

Изучение процессов, протекающих в конденсированной фазе, методом ТГА показало, что антипирены активизируют основную стадию термоокислительной деструкции волокон. В результате начальная температура и температура завершения процесса термолиза сдвигаются в область более низких температур на $40-60 \mathrm{~K}$ по сравнению с наблюдавшимися для исходного волокна. Вместе с тем деструкция модифицированных волокон протекает с несколько меньшими скоростями и после завершения основной стадии термолиза ( $623 \mathrm{~K})$ характеризуется повышенным выходом коксового остатка (КО) (табл. 1).

Эти данные позволяют предполагать, что антипирены изменяют механизм разложения ВВ, при этом создаются условия для преимущественного протекания процесса дегидратации с изменением соотношения между летучими продуктами деструкции и КО. Выход КО увеличивается, а в составе летучих продуктов возрастает доля $\mathrm{CO}_{2}, \mathrm{H}_{2} \mathrm{O}$, за счет чего горючесть волокон снижается.

У ПКМ, армированных огнезащищенными волокнами, выход КО также возрастает после завершения основной стадии разложения. Кроме того, в присутствии антипиренов изменяется структура образовавшегося кокса. Для материалов, армированных неогнезащищенным ВВ, характерна однородная структура кокса, в которой волокно и полимерная матрица отдельно не различаются (рис. 1, а) и, наоборот, в структуре кокса ПКМ, армированного ОЗВ-6, волокно четко сохраняет свою структуру, при этом коксовый слой значительно увеличивается (рис. 1,б), что препятствует выходу горючих продуктов из зоны пиролиза.

Увеличение выхода $\mathrm{CO}_{2}$ и $\mathrm{H}_{2} \mathrm{O}$ в процессе дегидратации подтверждается данными СПГХ. Дегидратация всех исследуемых огнезащищенных гидратцеллюлозных волокон смещается на $30-100 \mathrm{~K}$ в сторону более низких температур и протекает с бо́льшим выходом воды, чем дегидратация немодифицированных волокон (табл. 2). Выделение горючего газа $\mathrm{CO}$ из первых четырех типов огнезащищенных волокон (О3В-1ОЗВ-4) значительно уменьшается против его выхода из исходного волокна, а из ОЗВ-6 и ОЗВ-7 соответствует последнему. Однако эффект от модификации волокон антипиренами снижается в композициях со связующим. Для ПКМ, армированных огнезащищенными волокнами, существенного увеличения $\mathrm{H}_{2} \mathrm{O}$ и снижения выхода $\mathrm{CO}$ не отмечено. 

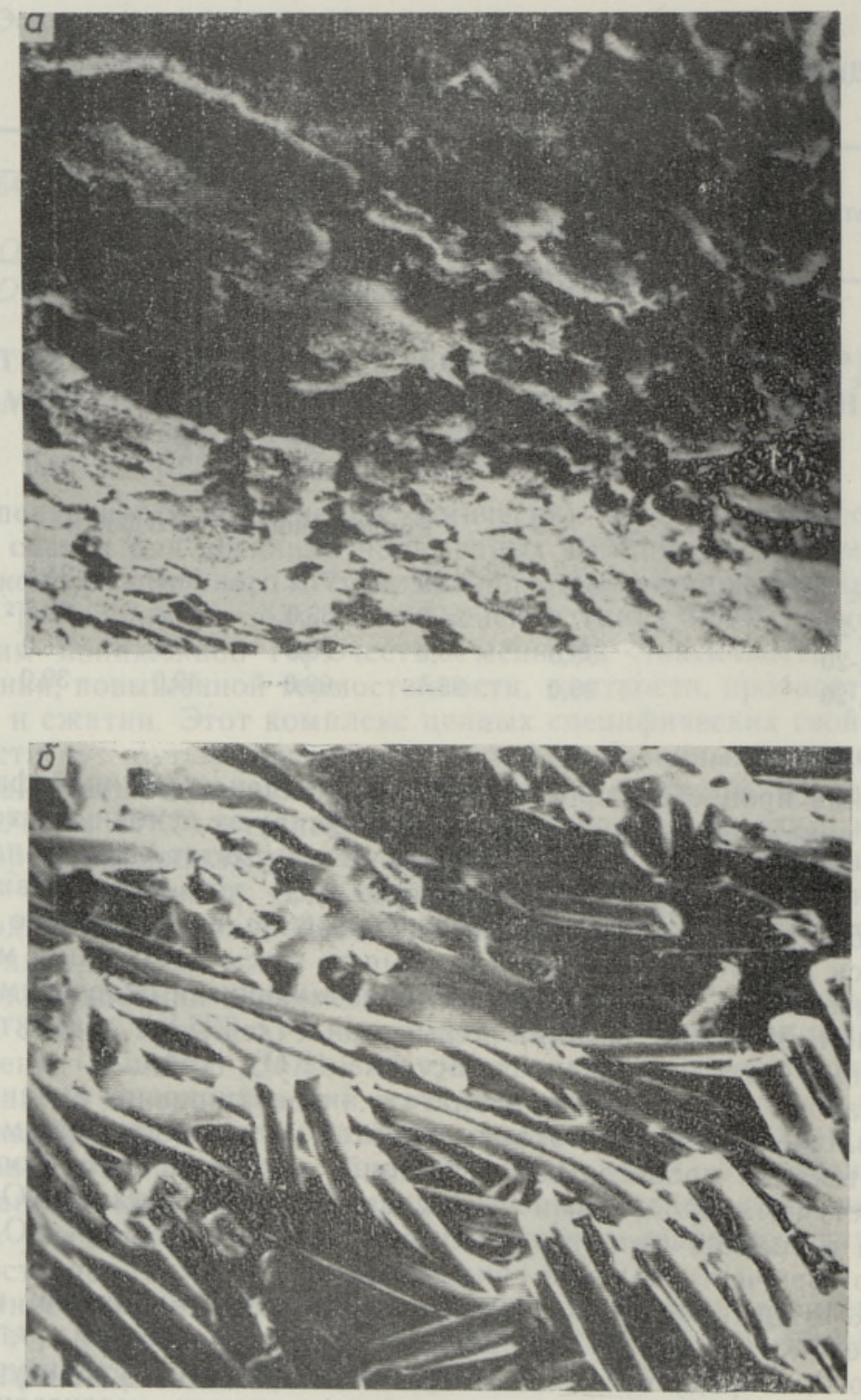

Рис. 1. Структура кокса эпоксидных ПКМ, армированных исходным (а) и огнезащищенным (б) вискозным волокном.

Бо́льшее влияние оказывают антипирены на изменение температурного режима дегидратации ПКМ.

Анализ данных СПГХ (табл. 2), определяющих эффект влияния антипиренов на изменение количества летучих продуктов и температуры дегидратации, показал, что выход $\mathrm{H}_{2} \mathrm{O}$ при дегидратации огнезащищенных волокон определяется не количеством антипирена на волокне, а химической природой антипирена. Так, волокна О3В-1, О3В-2, О3В-6 и О3В-7, несмотря на различное содержание антипиренов (от 20 до $44 \%$ мас.), имеют почти одинаковые значения $\Delta V_{\mathrm{H}_{2} \mathrm{O}}$. Более того, эффект влияния одного и того же антипирена фосфорнокислой соли полиэтиленполиамина на выход воды с увеличением его количества с 25,3 до $30,5 \%$ на волокне снижается с $+42,0$ до $+27,0$ для ОЗВ-2 и ОЗВ-3 соответственно. Однако температура дегидратации с возрастанием количества антипирена на волокне снижается с $496 \mathrm{~K}$ для О3В-2 до $483 \mathrm{~K}$ для О3В-3. 
Эффект влияния антипирена, \% от данных для немодифицированного вискозного волокна

\begin{tabular}{|c|c|c|c|c|c|c|c|c|}
\hline \multirow[b]{2}{*}{ Материал } & \multicolumn{2}{|c|}{$\mathrm{H}_{2} \mathrm{O}$} & \multicolumn{2}{|c|}{$\mathrm{CO}_{2}$} & \multicolumn{2}{|c|}{$\mathrm{CO}$} & \multirow{2}{*}{$\begin{array}{c}\text { Привес } \\
\text { анти- } \\
\text { пирена, } \\
\% \text { мас. }\end{array}$} & \multirow[b]{2}{*}{$\Delta \mathrm{K} И$} \\
\hline & $\Delta V$ & $\Delta T$ & $\Delta V$ & $\Delta T$ & $\Delta V$ & $\Delta T$ & & \\
\hline
\end{tabular}

Волокна

$\begin{array}{llllllllr}\text { O3B-1 } & +42,4 & -26,6 & +13,4 & -29,3 & -86,6 & - & 44,5 & +102,0 \\ \text { O3B-2 } & +42,0 & -20,9 & -43,7 & -20,5 & -70,0 & - & 25,3 & +78,2 \\ \text { O3B-3 } & +27,0 & -25,6 & -54,8 & -25,8 & -73,8 & - & 30,5 & +115,2 \\ \text { O3B-4 } & +51,1 & -36,2 & -51,6 & -36,5 & -94,8 & - & 36,1 & +147,8 \\ \text { O3B-6 } & +42,4 & -9,0 & -25,0 & -3,0 & -0,02 & -3,0 & 20,0 & +8,0 \\ \text { O3B-7 } & +41,9 & -4,5 & -17,0 & -16,1 & -21,7 & -12,1 & 20,0 & -\end{array}$

Композиционные материалы

$\begin{array}{lrllllll}\text { ОЗВ-2+ЭД- } 20 & +4,2 & -15,5 & +8,0 & -12,0 & +4,2 & - & +29,5 \\ \text { ОЗВ-3+ЭД-20 } & +2,2 & -17,2 & +4,0 & +17,2 & +2,2 & - & +50,0 \\ \text { ОЗВ-4+ЭД- } 20 & +2,9 & -39,6 & +2,4 & - & +3,0 & - & +16,4 \\ \text { ОЗВ-6+ЭД-20 } & +11,3 & -7,3 & -8,1 & - & +14,9 & - & +24,6\end{array}$

Прослеживается корреляция между кислородным индексом (КИ), выходом воды и температурой дегидратации (рис. 2). Эти данные свидетельствуют, что применяемые антипирены изменяют механизм разложения ВВ, способствуя протеканию его по реакции дегидратации, что приводит к снижению выхода горючих продуктов, увеличению выхода КО и изменению его структуры, а следовательно, и к снижению горючести волокон и ПКМ на их основе. Поэтому все исследованные антипирены могут использоваться для снижения горючести ПКМ. Технологически более просто осуществляется получение модифицированных волокон ОЗВ-4-О3В-7.

При армировании ПКМ полиакрилонитрильными волокнами (ПАН) к задаче снижения горючести материала добавляется задача уменьшения выхода токсичных газов пиролиза, в частности HCN. В этом плане большими преимушествами обладают волокна, полученные методом химической модификации, например, привитые сополимеры целлюлозы и ПАН волокна $\left.{ }^{3}\right]$. Нами для армирования фенольной смолы применялись волокна, представляющие собой сополимер акрилонитрила $(60 \%$ мас.) с винилхлоридом (40\% мас.) - $\mathrm{AH} / \mathrm{BX}$.

Для определения влияния регулярности строения полимера применялась также гибридная армирующая система - механическая смесь, содержащая одинаковое с сополимерным волокном количество акрилонитрила $(60 \%$ мас.) и винилхлорида $(40 \%$ мас.), из полиакрилонитрильного и поливинилхлоридного волокон (ПАН/ПВХ).

Рис. 2. Взаимосвязь кислородного индекса с показателями дегидратации.

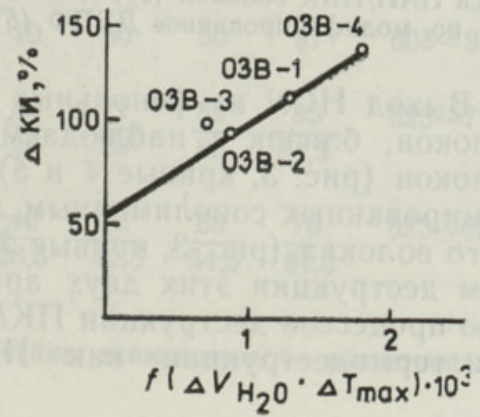


Сополимерное AH/BX волокно дает даже бо́льший выход $\mathrm{HCN}$, чем волокно из гомополимера ПАН (рис. 3). Это можно объяснить тем, что при нагревании ПАН волокон наряду с химическими процессами происходят сложные структурные превращения, в результате которых выделение $\mathrm{HCN}$ в интервале температур 473-673 К осуществляется в основном из незациклизованных участков цепи с образованием двойных связей по реакции:

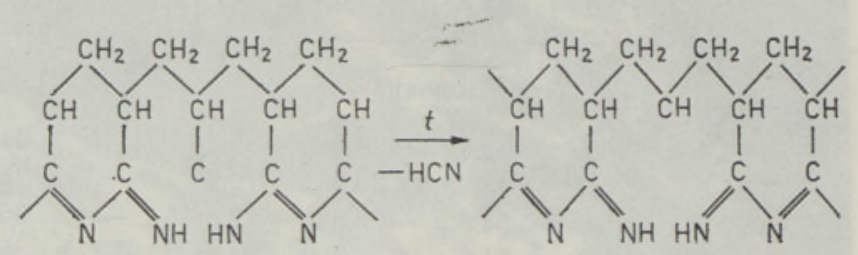

Введение хлорвинильных групп в макромолекулу ПАН<smiles>CCC(C#N)CC(I)C(Cl)(Cl)Cl</smiles>

препятствует циклизации вследствие появления несопряженных нитрильных групп. Это вызывает увеличение количества незациклизованных участков, в связи с чем выход НCN возрастает.

При пиролизе механической смеси ПАН/ПВХ волокон выход $\mathrm{HCN}$ уменьшается примерно в 6 раз по сравнению с АН/BX волокном при одинаковом содержании в них акрилонитрила. В этой армирующей системе возможно каталитическое влияние ПВХ на ускорение циклизации ПАН, а также взаимодействие выделяющихся при разложении компонентов смеси газов пиролиза.

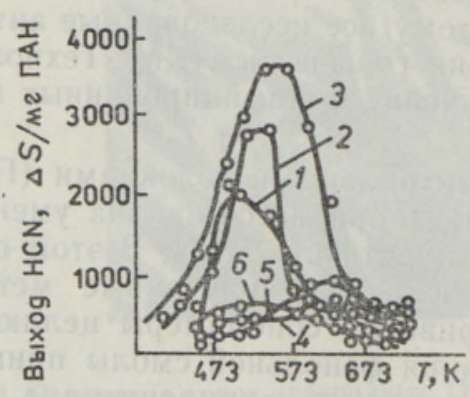

Рис. 3. Выход НСN из вискозных волокон и из ПКМ на их основе: ПАН волокно (1); $\mathrm{AH} / \mathrm{BX}$ волокно (2), ПКМ на основе $\mathrm{AH} / \mathrm{BX}$ волокна (3); механическая смесь ПАН/ПВХ волокон (4), ПКМ на основе смеси ПАН/ПВХ волокон (5); ПАН волокно, модифицированное ДБПФ (6).

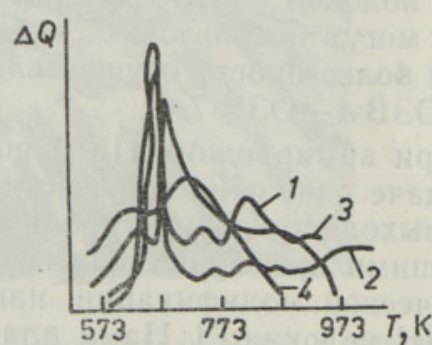

Рис. 4. Кривые ДТА: ПВХ волокно (I), механнческая смесь ПАН/ПВХ волокон (2), ПАН волокно (3), сополимерное $\mathrm{AH} / \mathrm{BX}$ волокно (4).

Выход НCN из фенольных ПКМ, армированных смесью ПАН/ПВХ волокон, близок к наблюдаемому при пиролизе армирующей смеси волокон (рис. 3 , кривые 4 и 5). В то же время выход $\mathrm{HCN}$ из ПКМ, армированных сополимерным АН/ВX волокном, выше, чем из армирующего волокна (рис. 3 , кривые 2 и 3 ). Это объясняется различным химизмом деструкции этих двух армирующих систем, приводящим к различию процессов деструкции ПКМ на их основе. По данным ДТА (рис. 4), при термодеструкции как ПАН, так и смеси ПАН/ПВХ волокон в 
области одних и тех же температур наблюдается экзопик, характерный для процесса циклизации ПАН [4]. У сополимерного АН/BX волокна в области этих же температур наблюдается эндопик, характерный для процесса дегидрохлорирования, а экзопик, соответствующий циклизации, смещается в область более высоких температур. А так как деструкция фенольной смолы происходит при более высоких температурах по сравнению с $\mathrm{AH} / \mathrm{BX}$ волокном, то выделяющийся в процессе дегидрохлорирования $\mathrm{HCl}$, накапливаясь в объеме материала, может приводить к деполимеризации ПАН и повышению выхода $\mathrm{HCN}$ по сравнению с наблюдаемыми только из АН/ВХ волокна. Таким образом, не только химический состав армирующих волокон, но и строение макромолекулы оказывает влияние на токсичность и горючесть ПКМ на их основе. Так, температура пламени эпоксидных ПКМ на основе АН/BX волокон на $40 \mathrm{~K}$ выше температуры пламени ПКМ, армированных смесью ПАН/ПВХ волокон (1453 K для АН/ВХ и $1413 \mathrm{~K}$ для ПАН/ПВХ). У ПКМ на основс смеси ПАН/ПВХ волокон ниже массовые скорости пиролиза и больше выход КО. Например, при $673 \mathrm{~K}$ : массовые скорости для АН/BX $0,65 \mathrm{c}^{-1}$, для ПАН/ПВХ - 0,4 $\mathrm{c}^{-1}$; $\mathrm{KO}-47,0$ и 56,0\% соответственно.

Эффективным способом снижения количества выделяющейся $\mathrm{HCN}$ является также модификация ПАН волокна дибромпропилфосфатом (ДБПФ) (рис. 3, кривая 6). Применение ДБПФ уменьшает линейную скорость распространения пламени с 1,2 до 0,8 мм/с (при 60\%-ном содержании кислорода), снижает потери массы при горении и увеличивает КИ.

Ранее установлено, что армирование эпоксидных ПҚМ капроном, модифицированным новолаком, повышает жесткость, устойчивость к действию сжимающих, растягивающих и ударных нагрузок по сравнению с немодифицированным капроном [5]. Изучение термоустойчивости и состава газов пиролиза нами осуществлялось методами ТГА и СПГХ соответственно (табл. 3 и 4). До температуры 523 К деструкции материала не происходит. Область интенсивной потери массы начинается с $573 \mathrm{~K}$ и выше. По данным СПГХ, при $573 \mathrm{~K}$ из исходного капронового волокна выделяется вода в результате разрыва концевых групп макро-

таблица 3

Данные термогравиметрического анализа

\begin{tabular}{|c|c|c|c|c|c|c|c|c|}
\hline \multirow[b]{2}{*}{ Материал } & \multicolumn{7}{|c|}{ Потери массы, \% } & \multirow[b]{2}{*}{$T_{\text {нач }}-T_{\text {конеч }}$} \\
\hline & $523 \mathrm{~K}$ & $573 \mathrm{~K}$ & $623 \mathrm{~K}$ & $673 \mathrm{~K}$ & $723 \mathrm{~K}$ & $773 \mathrm{~K}$ & $873 \mathrm{~K}$ & \\
\hline
\end{tabular}

Ненаполненная эпоксидная смола ЭД- 20

Исходное капроновое волокно

Модифицированное капроновое волокно

Композиционный матернал на основе исходного волокна

Композиционный материал на основе модифицированного волокна

$\begin{array}{ccccccccc}8 & 14 & 25 & 47 & 55 & 59 & 66 & 483-743 \\ & 2,5 & 4 & 5 & 13 & 63 & 75 & 97 & 593-913 \\ & 2 & 2,5 & 4,0 & 10 & 30 & 50 & 97 & 603-943 \\ & \frac{3}{5,25} & \frac{6}{9} & \frac{13}{15} & \frac{38}{26} & \frac{71}{59} & \frac{82}{66} & \frac{85}{81,5} & 523-773 \\ & \frac{4}{5} & \frac{9}{8,25} & \frac{18}{14,5} & \frac{40}{28,5} & \frac{62}{42,5} & \frac{68}{54,5} & \frac{76}{81,5} & 523-683\end{array}$

Примечание: числитель - экспериментальное значение, знаменатель - расчетное значение. 
Выход летучих продуктов пиролиза из капроновых волокон и композиционных материалов на их основе, мкг/мг

\begin{tabular}{l|l|l|l|l|l|l|l|l}
\hline Материал & $T, \mathrm{~K}$ & $\mathrm{CO}$ & $\mathrm{NH}_{3}$ & $\mathrm{CO}_{2}$ & $\mathrm{H}_{2} \mathrm{O}$ \\
\hline
\end{tabular}

Ненаполненная эпоксидная смола ЭД-20

Исходное капроновое волокно вое волокно

Композиционный материал на основе исходного волокна

Композиционный материал на основе модифицированного волокна

$\begin{array}{lcrrr}523 & - & \overline{2} & - & - \\ 573 & 3,0 & 2,48 & - & 1,47 \\ 623 & 20,17 & 17,47 & \text { следы } & 21,49 \\ 673 & 15,96 & 15,10 & 4,52 & 10,33 \\ 773 & 36,63 & 16,31 & 9,36 & 20,08\end{array}$

$\begin{array}{rrrrr}523 & - & - & - & - \\ 573 & - & - & - & 4,80 \\ 623 & 3,5 & 2,68 & 2,0 & 5,93 \\ 673 & 17,2 & 17,4 & 70,2 & 25,0\end{array}$

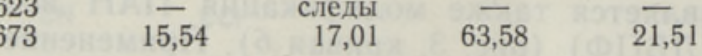

$\begin{array}{lllll}523 & - & - & - & - \\ 573 & - & - & - & \text { следы } \\ 623 & 10,40 & 13,03 & \text { следы } & 69,04 \\ 673 & 30,27 & 30,68 & 22,13 & 115,24 \\ 773 & 40,36 & 23,59 & 22,56 & 114,52\end{array}$

$\begin{array}{lllll}523 & - & - & - & - \\ 573 & - & - & - & 18,19 \\ 623 & - & - & - & 26,79 \\ 673 & \text { следы } & \text { следы } & \text { следы } & 44,89\end{array}$

молекулы поликапроамида. При более высоких температурах (623 K и выше) происходит выделение других летучих продуктов (CO, $\mathrm{CO}_{2}, \mathrm{NH}_{3}$ ) пиролиза. Введение немодифицированного капрона в смолу инициирует процесс разложения связующего, так как экспериментальные потери массы ПКМ при всех исследуемых температурах превышают расчетные (табл. 3). Этот вывод подтверждается данными СПГХ (табл. 4). Так, ПКМ на основе исходного волокна только при температуре $623 \mathrm{~K}$ имеют выходы $\mathrm{CO}, \mathrm{NH}_{3}$ и $\mathrm{CO}_{2}$, соответствующие аддитивным значениям. Однако выход воды и при этой температуре выше расчетного. С повышением температуры пиролиза ( $673 \mathrm{~K})$ выход летучих продуктов (за исключением $\mathrm{CO}_{2}$ ) превышает расчетные значения в 2-6 раз (табл. 4).

Модифицированный новолаком капрон термически более устойчив, чем исходный. Экзотермический эффект, соответствующий процессу термоокислительной деструкции модифицированного капрона, достигает максимума при $673 \mathrm{~K}$, и под влиянием этой температуры, по данным СПГХ, начинается выделение газообразных $\mathrm{CO}, \mathrm{NH}_{3}, \mathrm{CO}_{2}$ и $\mathrm{H}_{2} \mathrm{O}$. Из модифицированного капрона и ПКМ на его основе меньше выделяется газообразных продуктов разложения, в частности, одновременно уменьшаются выходы воды в интервале температур $523-673 \mathrm{~K}$ и горючетоксичного СО. Добавка новолака снижает и общий выход $\varepsilon$-капролактама, как для модифицированного волокна, так и для ПКМ на его основе, - на $30 \%$ по сравнению с исходным волокном без изменения 
температурного режима (рис. 5). Эти два факта свидетельствуют о том, что новолачная фенолоформальдегидная смола выступает в качестве термостабилизатора, ингибируя разрыв амидных связей в процессе пиролиза.

Модифицированное волокно и ПКМ на его основе во всем исследованном интервале температур имеют потери массы меньше, чем немодифицированное волокно и ПКМ, им армированные (табл. 3). По завершении основной стадии термолиза $(773 \mathrm{~K})$ потери массы ПКМ с модифицированным капроном составляют $68 \%$, а с немодифицированным $82 \%$. Отклонение от аддитивности потерь массы обусловлено, как и в случае с исходным капроном, инициирующим влиянием волокна на деструкцию системы.

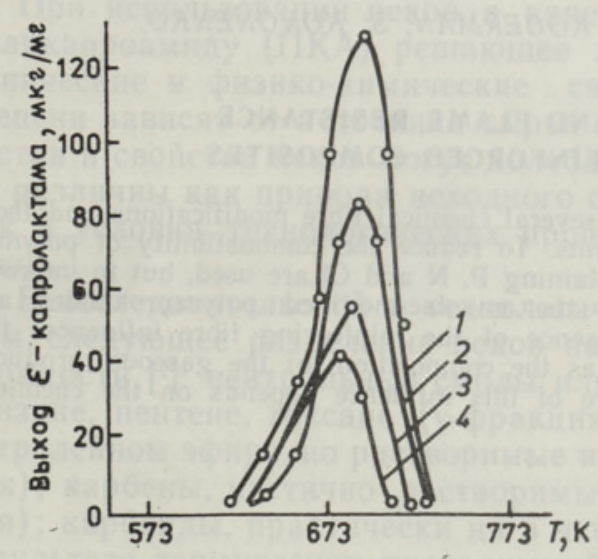

Рис. 5. Выход $\varepsilon$-капролактама из волокон и ПКМ на их основе: исходное капроновое волокно (1), модифицированное новолаком капроновое волокно (2), ПКМ на основе исходного капронового волокна (3), ПКМ на основе моднфицированного волокна (4).
Повышение термостойкости позволяет расширить температурный интервал эксплуатации ПКМ на 50 K. Так, ПКМ на основе модифицированного капрона сохраняют прочность до $473 \mathrm{~K}$, а на основе исходного - до $423 \mathrm{~K}$ (рис. 6).

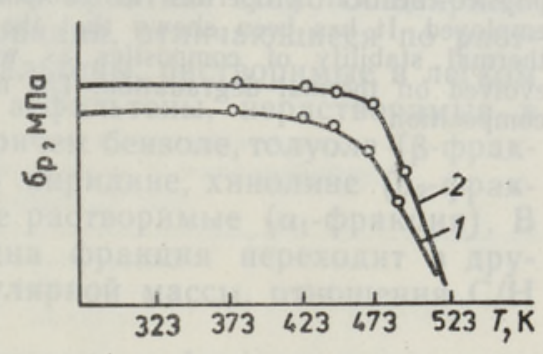

Рис. 6. Влияние температуры на изменение прочности ПКМ на основе исходного

(1) и модифицированного (2) волокон.

Подытоживая результаты данного исследования, можно сделать вывод, что волокно влияет на стабильность свойств ПКМ при воздействии высоких температур, а также на состав выделяющихся при деструкции летучих продуктов. Характер этого влияния зависит от химического состава волокна. Применяя модифицированные химические волокна, можно получать ПКМ с комплексом заранее заданных свойств, в частности, по термостойкости и устойчивости к горению.

\section{Л И ТЕ РА Т У РА}

1. Глухова Л. Г., Артеменко С. Е., Лютов В. А., Лобадин В. Я. Комплексная система отходов вискозных волокон // Хим. волокна, 1986, № 6, 36-39.

2. Панова Л. Г., Артеменко С. Е., Халтуринский Н. А., Берлин Ал. Ал. Полимерные композиционные материалы пониженной горючести, армированные химическими волокнами // Успехи химин, 1988, VII, вып. 7, 1191-1200.

3. Когерман A. Пиролизная газовая хроматография в исследовании термических свойств полимеров // Изв. АН ЭССР. Хим., 1984, 33, № 4, 235-243.

4. Термо-, жаростойкие и негорючие волокна. М., 1978.

5. Степанов В. В., Сперанский А. А., Герасимов Л. С., Хутарева Г. В. Свойства полиамидных нитей, модифицированных фенолоформальдегидным новолачным олигомером // Хим. волокна, 1978, № 6, 51-53.

Саратовский политехнический институт

\section{Ннститут химии}

Академии наук Эстонской ССР
Поступила в редакцию 4/IV 1989 
L. PANOVA, Serafima ARTEMENKO, Aili KOGERMAN, S. KONONENKO,

L. SKREBNEVA, O. KIRRET

\section{KEEMILISTE KIUDUDEGA ARMEERITUD POLOMEERSETE KOMPOSIITIDE TERMILINE JA TULEKINDLUS}

Artiklis on juttu mitmete keemiliste kiudude modifikatsioonide efektiivsuse uurimisest ja nende kasutamisest polümeersete vaikude armeerimisel. Polümeersete komposiitide pōlevuse vähendamiseks on kasutatud $\mathrm{P}, \mathrm{N}, \mathrm{Cl}$ sisaldavaid modifitseeritud keemilisi kiude, aga komposiitide füüsikalis-mehaaniliste omaduste parandamiseks novolakiga modifitseeritud polükaproamiide. On näidatud, et armeeriva kiu olemasolu mõjub komposiidi stabiilsusele kõrgel temperatuuril, samuti termodestruktsioonil eralduvate gaasiliste ainete koostisele. Mõju iseloom sõltub kiu keemilisest koostisest.

L. PANOVA, Serafima ARTEMENKO, Aili KOGERMAN, S. KONONENKO,

L. SKREBNEVA, O. KIRRET

\section{THERMAL STABILITY AND FLAME RESISTANCE OF CHEMICAL FIBRE-REINFORCED COMPOSITES}

The article deals with the efficiency of several chemical fibre modifications and their application of reinforcement of polymer resins. To reduce the combustibility of polymer composites, the modified chemical fibres containing $\mathrm{P}, \mathrm{N}$ and $\mathrm{Cl}$ are used, but to improve physico-chemical properties of composites the novolac-modified polycaproamides are employed. It has been shown that the presence of the reinforcing fibre influences the thermal stability of composites as well as the composition of the gaseous products evolved on thermal degradation. The nature of this influence depends on the chemical composition, 